\title{
Tannin Extraction from Oak Gall and Evaluation of Anti-Oxidant Activity and Tannin Iron Chelation Compared with Deferoxamine Drug
}

\author{
Meghdad Payab*, Mohammad Javad Chaichi, Ome Leila Nazari, Fatemeh Yousefnejad Maleki \\ Department of Chemistry, Faculty of Chemistry, University of Mazandaran, Babolsar, Iran \\ Email address: \\ Meghdad.payab@gmail.com(M. Payab),Chaichi@umz.ac.ir(M. J. Chaichi), o.nazari@umz.ac.ir(O. L. Nazari), \\ fatemeh.maleki7090@gmail.com (F. Y. Maleki) \\ ${ }^{*}$ Corresponding author \\ To cite this article: \\ Meghdad Payab, Mohammad Javad Chaichi, Ome Leila Nazari, Fatemeh Yousefnejad Maleki. Tannin Extraction from Oak Gall and \\ Evaluation of Anti-Oxidant Activity and Tannin Iron Chelation Compared with Deferoxamine Drug. Journal of Drug Design and Medicinal \\ Chemistry. Vol. 5, No. 2, 2019, pp. 18-25. doi: 10.11648/j.jddmc.20190502.11
}

Received: May 29, 2019; Accepted: July 10, 2019; Published: August 6, 2019

\begin{abstract}
In this study, tannins were extracted by two methods (soaking and Soxhlet) with three different solvents (water, methanol and aqueous methanol 50\%) and the three kind plant (walnut shell, gall oak and walnut leaves), that the highest extraction efficiency $(82.08 \%$ ) was related to extraction with aqueous methanol by Soxhlet method from the oak galls. Although the results of soaking were nearly to the Soxhlet. One oak Gall extract was evaluated by Lowenthal method that the result was showed that reducing materials such as tannins are $26.14 \%$. The extracted was evaluated by Folin-Ciocalteu method that suggests phenolic compounds in the extract was $15.27,(61.07 \pm 7.12 \mathrm{mg}$ compared to gallic acid). Result of evaluation of antioxidant activity of the extracted showed the high antioxidant properties of tannins compared to ascorbic acid at less than $100 \mathrm{ppm}$ concentrations, but these properties comparable to ascorbic acid of the higher concentrations, so a lower dose of the extract was may be helpful. The chelation properties of the iron ions at low concentrations of iron (III), oak was showed better performance compared to Deferoxamine but Deferoxamine due to complex formation with higher stoichiometry (1: 6) at high concentrations of Fe (III), has performed better than the oak.
\end{abstract}

Keywords: Tannin, Oak Gall, Deferral, Iron chelation, Thalassemia

\section{Introduction}

Tannins are high molecular weight polyphenolics found in higher plants including many plants used as foods and feed [1]. Tannins ingested with the diet by humans or animals may affect protein utilization by forming insoluble complexes with protein, iron utilization by complexion with iron, and biological anti-oxidant status by participating in redox reactions [2]. Tannins may contribute to the chemical defenses that minimize damage to plants by insect and mammalian herbivores [3]. Their importance in nutrition and in ecological processes makes qualitative and quantitative analysis of tannins critical to studies of plant nutritional quality and plant ecology [4]. In addition tannins are an antioxidant. Antioxidants may be defined as compounds that inhibit or delay the oxidation of other molecules by inhibiting the initiation or propagation of oxidizing chain reactions. Antioxidants can also protect the human body from free radicals and reactive oxygen species (ROS) effects [5]. At the present time, the most commonly used antioxidants are butylated hydroxyanisole (BHA), butylated hydroxytoluene (BHT), propyl gallate (PG) and tert butyl hydroquinone (TBHQ). Their safety of these antioxidants has recently been questioned due to toxicity [6]. Besides that BHA and BHT have suspected of being responsible for liver damage and carcinogenesis [7, 8] Also, BHT had little effect on mutagenicity at low concentrations, but significantly increased their mutagenicity at high concentrations [9]. It was reported that BHT may cause internal and external hemorrhaging at high dose that is severe enough to cause death in some strains of mice and guinea-pigs [10]. Therefore, there is a growing interest on natural and safer 
antioxidants [11-13].

Food antioxidants such as a-tocopherol, ascorbic acid, [14] carotenoids, amino acids, peptides, proteins, flavonoids and other phenolic compounds might also play a significant role as physiological and dietary antioxidants, thereby augmenting the body's natural resistance to oxidative damage [15]. Development of safer natural antioxidants from extracts of oilseeds, spices and other plant materials that can replace synthetic antioxidants has been of interest [16]. Additionally, there has also been interest in preserving endogenous antioxidants in food products both for stabilization and for nutritional purposes [17]. Natural antioxidants are known to exhibit a wide range of biological effects including antibacterial, antiviral, anti-inflammatory, ant allergic, antithrombotic and vasodilators activities. In fact, a fundamental property important for life is the antioxidant activity and this property may give rise to anti carcinogenicity, anti-mutagenicity and antiaging activity, among others [18]. The antioxidant activity of phenolic compounds is mainly attributed to their redox properties, which allow them to act as reducing agents, hydrogen donors and quenchers of singlet oxygen. In addition, they may also possess metal chelation properties [19]. Phenolic acids are secondary metabolites widely distributed in the plant kingdom and are second only to flavonoids in terms of their dominance, suggesting that naturally occurring. Tannic acid is a plant polyphenol which is found, along with other condensed tannins, in several beverages including red wine, beer, coffee, black tea, green tea, and many foodstuffs such as grapes, pears, bananas, sorghum, black-eyed peas, lentils and chocolate [20]. Similar to many polyphenols, tannic acid has been shown to possess antioxidant [21-24], anti-mutagenic $[22,25,26]$ and anti-carcinogenic properties [27-30]. The antioxidant mechanism of tannic acid is still far from being fully understood; therefore, it requires further investigation. For example, in the presence of copper ions, tannic acid acts either as a prooxidant, promoting DNA damage [29], or as an antioxidant, suppressing hydroxyl radical formation $[22,31,32]$.

Iron is required for a number of essential enzyme systems operative in the erythrocytic trophozoite, including dihydroorotate dehydrogenase for the synthesis of pyrimidine $[33,34]$, phosphoenol pyruvate carboxykinase in $\mathrm{CO}_{2}$, fixation, [35-37] and cytochrome oxidase of the mitochondrial electron transport system [36].

Two common inhibitors of $\mathrm{Fe}$ absorption are tannins and phytate. These components form complexes with Fe within the lumen, reducing $\mathrm{Fe}$ bioavailability. $\mathrm{Fe}^{2+}$ is more bioavailable than $\mathrm{Fe}^{3+}$ because it is more soluble at physiological $\mathrm{pHs}$ and because it has a lower affinity for ligands that may inhibit absorption [38]. Presumably, Fe binds to the adjacent hydroxyls on the galloyl group in the tannins. The galloyl group has been implicated as the structure responsible for the inhibition of Fe absorption by phenolic compounds in foods [39]. The Fe-galloyl complex forms a violet color with an absorbance maximum at

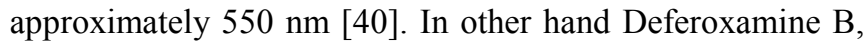

a naturally occurring trihydroxamic acid derived from cultures of Streptomyces pilosus, is the only drug currently available for clinical use as an iron chelator. A generally safe and nontoxic agent, it must be administered by continuous parenteral infusion to be effective; daily doses of up to 150 $\mathrm{mg} / \mathrm{kg}$ are used for therapy of iron overload [41, 42].

This study is aimed to investigate the antioxidant properties of tannin's Oak gall and then iron chelating properties of tannins extracted compared with Deferoxamine B.

\section{Material and Methods}

\subsection{Chemicals}

The stable free radical 1,1-diphenyl-2-picryl-hydrazyl (DPPH), ascorbic acid, ammonium molybdate, folin and ciocalteu reagent and gallic acid were obtained from Sigma (Sigma- Aldrich, St. Louis, Missouri, USA). Methanol, sulfuric acid and trisodium phosphate dodecahydrate, indigo carmine, potassium permanganate were purchased from Merck (Darmstadt Germany). Tannic acid, ethanol, sodium hydroxide, ferric ammonium sulfate dodecahydrate and sodium carbonate were purchased from Fluka (Buchs, Switzerland). All other chemicals used were in analytical grade and obtained from Sigma-Aldrich, Fluka or Merck. The drug of deferoxamine B was prepared from the pharmaceutical company of the Jabir Ibn Haiyan (Tehran, Iran).

\subsection{Tannin Extraction Method}

The Oak gall were purchased from local market and washed with distilled water at room temperature. They are converted into powder after to dry in the air. Five grams of powdered were extracted with $90 \mathrm{~mL}$ of water: methanol (1:1) as extract solvent by using the Soxhlet apparatus for 6 hours. Then the solvent was evaporated with a rotavapor apparatus at $60^{\circ} \mathrm{C}$ and a reduced pressure of $10 \mathrm{~mm} \mathrm{Hg}$.

\subsection{Assay of Total Phenolic Content}

\subsubsection{Determination of Tannins Using Lowenthal Method}

This method used to reduce the tannins feature that is performed by titration with permanganate of known normality. It is used Indigo carmine to determine the end point that the solution changed color from blue to yellow in the end point of the titration [55]. Tannin content (T\%) in the sample is calculated according to the following equation:

$$
\mathrm{T}(\%)=\frac{\left(\mathrm{V}-\mathrm{V}_{0}\right) \times \mathrm{N} \times 0.004157 \times \mathrm{V}_{\mathrm{E}} \times 100}{\mathrm{~g} \times 2.5}
$$

Where $\mathrm{V}$ is the volume of aqueous solution of permanganate for titration of the sample and $\mathrm{V}_{0}$ is the volume of aqueous solution of permanganate for titration of the blank that unit is $\mathrm{mL}, \mathrm{N}$ is the normality of the number of potassium permanganate, $4.157 \times 10^{-3}$ is equivalent gram of the tannins in $1 \mathrm{~mL}$ of aqueous solution of permanganate, $\mathrm{V}_{\mathrm{E}}$ is the total volume of the solution was extracted during the extraction 
process in $\mathrm{mL}, \mathrm{g}$ is the mass of the sample in gram. 2.5 volume of extracted for titration is $\mathrm{mL}$. Add $2.5 \mathrm{~mL}$ of the deionized water was added to $100 \mathrm{~mL}$ volumetric flask. Then was added $2.5 \mathrm{~mL}$ of Indigo carmine solution and thereafter added $75 \mathrm{~mL}$ deionized water into the flask. Then the aqueous solution of potassium permanganate $[0.1 \mathrm{~N}]$ used for titration until the color of the solution change from blue to green. Then a few drops titrant is added until the solution color shift to golden yellow.

\subsubsection{Determination of Total Phenolic Content Using Folin and Denis Method}

The amount of total phenolic in extracts was determined with the Folin-Ciocalteu reagent. Gallic acid was used as a standard and the total phenolic were expressed as $\mathrm{mg} / \mathrm{g}$ gallic acid equivalents (GAE). The standard solution concentration of $0.01,0.02,0.03,0.04$ and $0.05 \mathrm{mg} / \mathrm{ml}$ of gallic acid were prepared in methanol. The standard solution concentration of 0.1 and $1 \mathrm{mg} / \mathrm{ml}$ of plant extract were also prepared in methanol and $0.5 \mathrm{ml}$ of each sample were introduced into test tubes and mixed with $2.5 \mathrm{ml}$ of a 10 fold dilute FolinCiocalteu reagent and $2 \mathrm{ml}$ of $7.5 \%$ sodium carbonate. The tubes were covered with parafilm and allowed to stand for 120 minutes at room temperature before the absorbance was read at $760 \mathrm{~nm}$. All determinations were performed in triplicate. The Folin-Ciocalteu reagent being sensitive to reducing compounds including polyphenols is producing a blue color upon reaction which is measured spectrophotometrically

\subsection{Investigate of the Antioxidant Properties of Tannins}

\subsubsection{DPPH Radical Scavenging Assay}

The free radical scavenging activity of the fractions was measured in vitro by 1,1 diphenyl-2-picrylhydrazyl (DPPH) assay.

About $0.3 \mathrm{mM}$ solution of DPPH in $100 \%$ ethanol was prepared and $1 \mathrm{ml}$ of this solution was added to $3 \mathrm{ml}$ of the fraction dissolved in ethanol at different concentrations $(25-400 \mu \mathrm{g} / \mathrm{ml})$. The mixture was shaken and allowed to stand at room temperature for $30 \mathrm{~min}$ and the absorbance was measured $517 \mathrm{~nm}$ using a spectrophotometer. The percentage of scavenging activity at different concentrations was determined and the IC50 value of the fractions was compared with that of ascorbic acid, which was used as the standard. Decreasing of the DPPH solution absorbance indicates an increase of the DPPH radical scavenging activity. DPPH radical-scavenging activity was calculated according to the following equation:

$$
\% \text { Inhibition }=\left(\left(\mathrm{A}_{0}-\mathrm{A}_{1}\right) / \mathrm{A}_{0} \times 100\right)
$$

Where $A_{0}$ was the absorbance of the control (without extract) and $A_{1}$ was the absorbance in the presence of the extract.

\subsubsection{Total Antioxidant Activity Assay}

Total antioxidant activity was estimated by phosphormolybdenum assay.

\section{i. Preparation of Molybdate Reagent Solution}

$1 \mathrm{ml}$ each of $0.6 \mathrm{M}$ sulfuric acid, $28 \mathrm{mM}$ sodium phosphate and $4 \mathrm{mM}$ ammonium molybdate were added in $20 \mathrm{ml}$ of distilled water and made up volume to $50 \mathrm{ml}$ by adding distilled water

\section{ii. Procedure}

Hydro alcoholic extract of Oak gall in different concentration ranging from $100 \mu 1$ to $500 \mu \mathrm{l}$ were added to each test tube individually containing $3 \mathrm{ml}$ of distilled water and $1 \mathrm{ml}$ of Molybdate reagent solution. These tubes were kept incubated at $95^{\circ} \mathrm{C}$ for $90 \mathrm{~min}$. After incubation, these tubes were normalized to room temperature for 20-30 min and the absorbance of the reaction mixture was measured at $695 \mathrm{~nm}$. Mean values from three independent samples were calculated for each extract. Ascorbic acid was used as positive reference standard.

\subsection{Investigate of the Complexation Effect of Tannins with Iron}

\subsubsection{Determination of Maximum Wavelength of Complex}

This procedure is performed in the $\mathrm{pH}$ range of human body (7.35 to 7.45). Previous research suggests because increases of the deprotonation of the ligand, the increase in alkaline $\mathrm{pH}$, thereby increasing the efficiency of the chelating. Two series solution of complex is provided to determine the maximum wavelength of the ligand: metal. In the first series of ligands to the metal, ligand concentration is considered high and low for the second series.

The first series is to preparation that added $10 \mathrm{~mL}$ of deionized water in a beaker of $100 \mathrm{ml}$ and then added $40 \mathrm{ml}$ ligand and $10 \mathrm{ml} \mathrm{Fe}$ (III) to it. In the second series also entered $10 \mathrm{ml}$ of deionized water and $10 \mathrm{ml}$ ligand and then $40 \mathrm{ml}$ iron (III) in $100 \mathrm{~mL}$ of beaker. Then the pHs of solution is adjusted in the human $\mathrm{pH}$ range by $0.1 \mathrm{~N} \mathrm{NaOH}$. Since the solutions are colored, it absorption is being obtained by scanning spectrophotometer in the range of 400 to $800 \mathrm{~nm}$.

\subsubsection{Determination of Mole Ratio of Ligand to Metal}

This method is used to evaluate the stoichiometry of the metal-ligand complex. In the first case (taking high ligand concentration) metal was kept constant while ligand was gradually increase. Then its $\mathrm{pH}$ adjusted with $\mathrm{NaOH} 0.1 \mathrm{~N}$. Absorbance was recorded on spectrophotometer on the observed maximum wavelength. Same procedure was repeated for the second case [taking low ligand concentration] in which ligand remained constant while metal was increased. In this method used of the tannic acid to the standard.

\section{Result \& Discussion}

\subsection{Figure [SciencePG-Level2-Single-line]}

In this study, extraction method was to use of the Soxhlet apparatus that efficiency of the extraction was $82.1 \%$. Tannin content is determined by Lowenthal method that accordingly, tannin percent is $26.1 \%$. As well as IR spectrum of the sample can be seen in "Figure 1". 


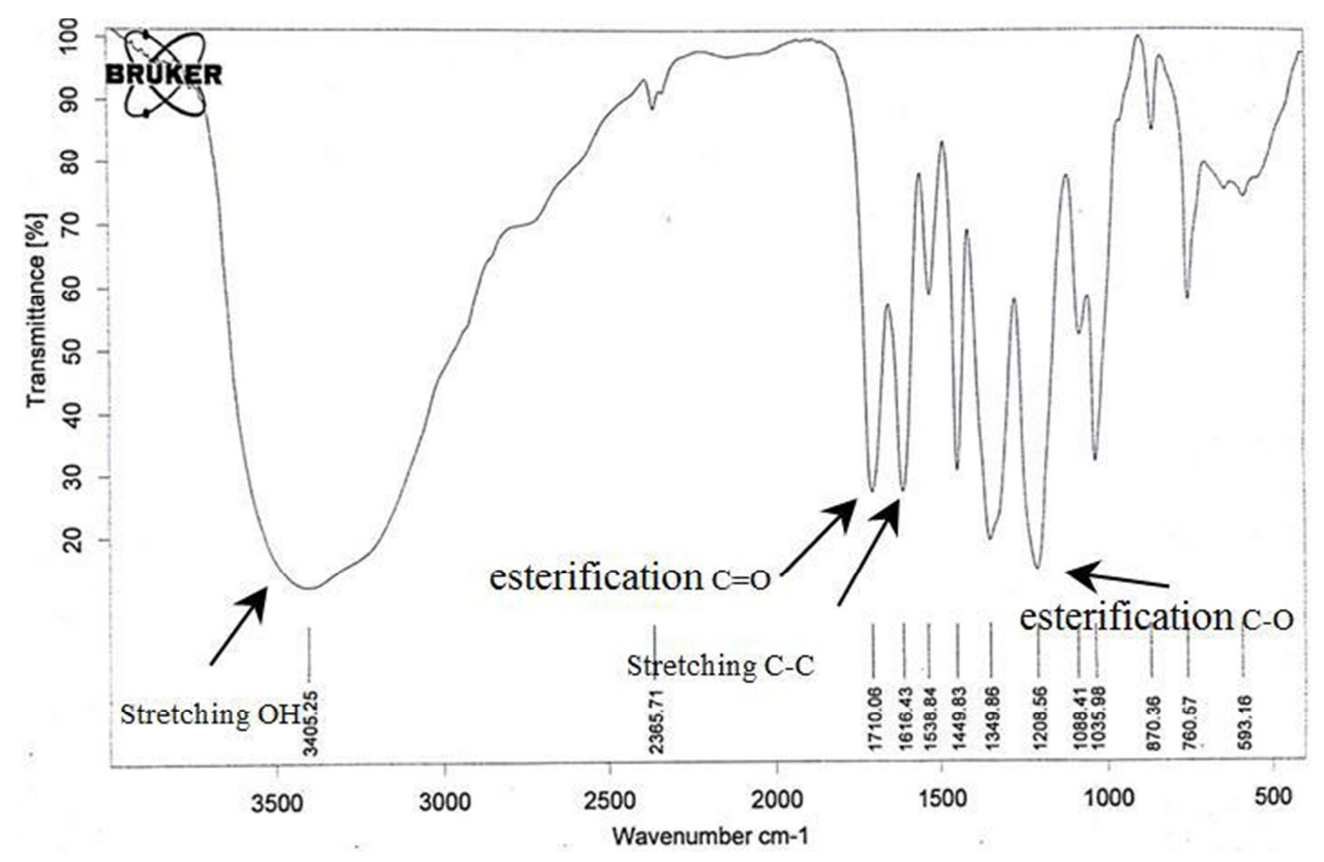

Figure 1. Tannin IR spectrum of the extracted from Oak gall.

According of Fig.1, the strong absorption spectrum has two peaks [at least] in $3803.87 \mathrm{~cm}^{-1}$ and $1203.33 \mathrm{~cm}^{-1}$ which is the frequency of stretching $[\mathrm{OH}]$ and $[\mathrm{CO}]$ respectively. Strong absorption at $3403.87 \mathrm{~cm}^{-1}$ of the hydroxyl group $[\mathrm{OH}]$ is esterified and broad peak. The esterification carbonyl group $[\mathrm{C}=\mathrm{O}]$ band is in the range of $1750-1730$ $\mathrm{cm}^{-1}$, but due to strong resonance bond with the aromatic ring, this has appeared in the shorter wavelength range [1704.42 $\mathrm{cm}-1]$. In addition, the ester group $[\mathrm{C}=\mathrm{O}]$ is a frequently observed in $1300 \mathrm{~cm}^{-1}$ to $1000 \mathrm{~cm}^{-1}$ that this group appeared in the $1211.08 \mathrm{~cm}^{-1}$ to $1035.37 \mathrm{~cm}^{-1}$. Methyl group [CH3] will appeared at approximately $1450-1375 \mathrm{~cm}^{-1}$ which appears in the range of the $1449.79 \mathrm{~cm}^{-1}$ to 1350.77 $\mathrm{cm}^{-1}$. Aromatic groups will appear in the range of approximately $3000 \mathrm{~cm}^{-1}$ which they are combined with a hydroxyl group and not detected but aromatic rings stretching band [C-C] can be seen in $1618.31 \mathrm{~cm}^{-1}$.

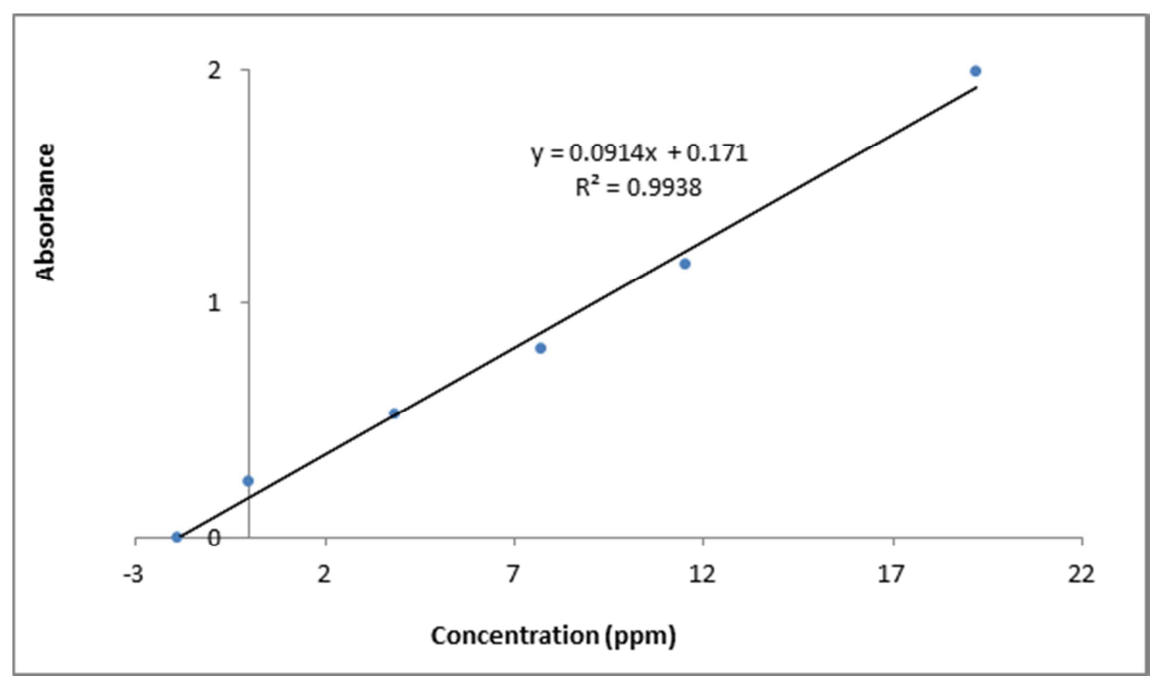

Figure 2. Standard addition curve for the determination of total phenolic content [Folin \& Ciocalteu method].

Standard addition curve used for the determination of total phenolic content (Folin \& Ciocalteu method) were prepared using different concentrations of Gallic acid equivalent (GAE) as shown in Figure 2. According to "Figure 2", the following equation is obtained:

$$
y=0.0910 x+0.1710\left[R^{2}=0.9938\right]
$$

From above the equation, the concentration of phenolic compounds in oak methanol extract obtained is $61.1 \pm 7.1 \mathrm{mg}$ of $\mathrm{GAE} / \mathrm{gm}$ of extract.

In the determination of antioxidant activity of the phenolic extract of Oak gall, capacity of total antioxidant extract compared with Ascorbic acid as standard is showed in the "Figure 3". 


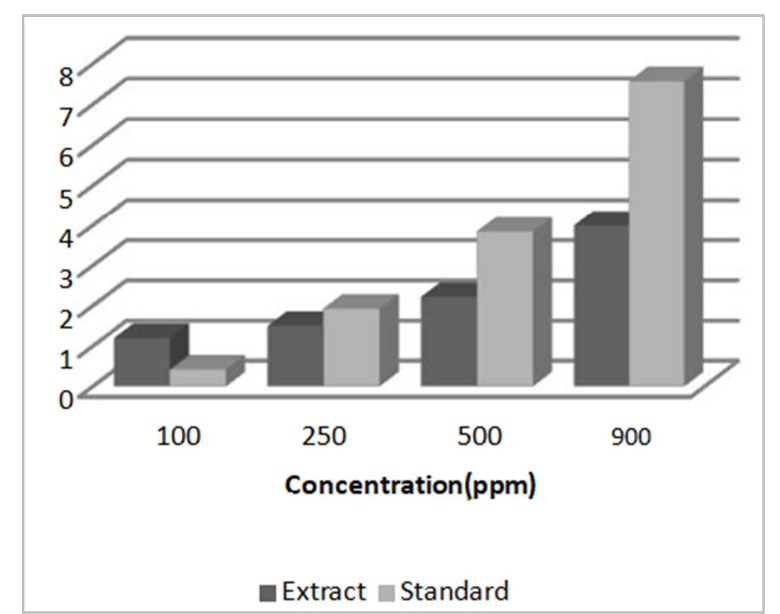

Figure 3. Capacity of total antioxidant extract compared with Ascorbic acid as standard.

According to the "Figure 3", antioxidant capacity of the Oak gall extract is dependent to the antioxidant concentration, So that, total antioxidant capacity is increased with increasing concentration. Total antioxidant properties of the contract is higher than ascorbic acid at low concentrations of the Oak gall extract $(100 \mathrm{ppm})$ but at high concentrations, total antioxidant capacity of the ascorbic acid was higher than that of the extract. In any case, the activity of extract is competitive with the standard. The DPPH has been widely used to evaluate the free radical scavenging effectiveness of various antioxidant substances [40]. With this method it was possible to determine the antiradical power of an antioxidant by measuring of a decreasing in the absorbance of DPPH at $517 \mathrm{~nm}$. Resulting a color change from purple to yellow, the absorbance decreased when the DPPH. Was scavenged by an antioxidant through donation of hydrogen to form a stable DPPH. molecule. In the radical form, this molecule had an absorbance at $517 \mathrm{~nm}$ which disappeared after acceptance of an electron or hydrogen radical from an antioxidant compound to form a stable diamagnetic molecule. "Figure 4" illustrates a significant decrease in the concentration of DPPH radical due to the scavenging ability of tannic acid and standard.

According to the "Figure 4" antiradical power of an antioxidant of the Oak gall extract is dependent to the antioxidant concentration, So that, free radical trapping ability of DPPH is increased with increasing concentration (approximately $200 \mathrm{ppm}$ ) but after this concentration, this was almost constant up to about $1000 \mathrm{ppm}$. The ability to free radical trapping of oak extract was much higher than ascorbic acid at low concentrations (approximately $10 \mathrm{ppm}$ ) and it was not comparable to the ascorbic acid but this difference is negligible at the higher concentration of $200 \mathrm{ppm}$ and these values were approximately equal. The DPPH trapping ability by extract was comparable with ascorbic acid at higher concentration of $200 \mathrm{ppm}$.

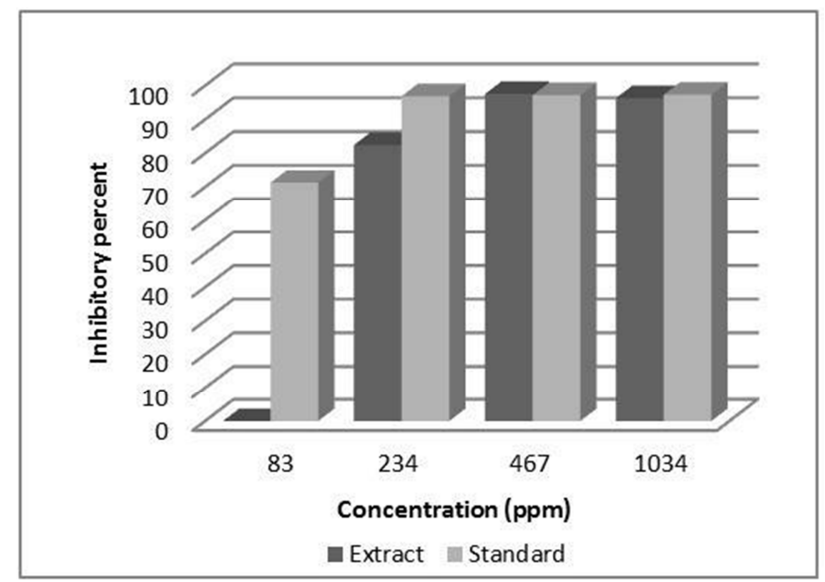

Figure 4. Scavenging ability of DPPH for tannic acid and standard.

To determine the stoichiometry of ligand to metal used molar ratio method. In this experiment, we first need to obtain the maximum wavelength of the solution in the range of the human's body $\mathrm{pH}$. Hence two series solution was prepared: In the first case (at high ligand concentration) metal was kept constant while ligand was gradually increase. Same procedure was repeated for the second case (taking low ligand concentration) in which ligand remained constant while metal was increased. "Figure 5" shows the absorbance versus wavelength for various ligands (Deferoxamine B (DFO), extract Oak gall and Tannic acid (TA)).

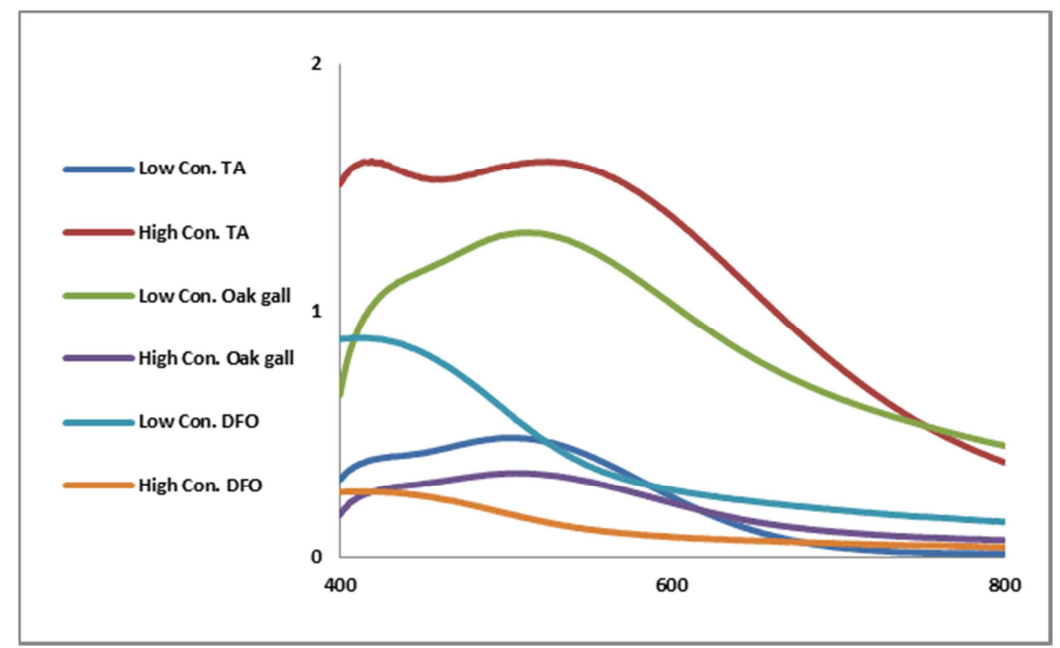

Figure 5. The absorbance versus wavelength for Deferoxamine [DFO], Oak gall and Tannic acid [TA]. 
According to "Figure 5", can be achieved the maximum wavelengths of the different complex.

"Table 1" shows a summary of the results. After determining the maximum wavelength of the complex, determined by the stoichiometry of the complex were preparing of different molar ratios of ligand to metal. If complex formation constant be reasonable, it is obtained two straight lines with different slopes. The intersection of these two lines is the ratio composition of the complex. This chart includes two curves which a curve shows at constant ligand concentration and the other curve is plotted at constant metal concentration. The following charts indicate results of this assessment.

Table 1. The maximum wavelength for Deferoxamine, Oak gall and Tannic acid.

\begin{tabular}{|c|c|c|c|}
\hline Ligand & Solution No. & Metal & maximum wavelength [nM] \\
\hline \multirow{2}{*}{ Tannic acid } & High Con. ${ }^{*}$ ligand & \multirow{6}{*}{ Fe(III) Solution } & 520 \\
\hline & Low Con. ligand & & 535 \\
\hline \multirow{2}{*}{ Extract (Oak gall) } & High Con. ligand & & 510 \\
\hline & Low Con. ligand & & 530 \\
\hline \multirow{2}{*}{ Deferoxamine B } & High Con. ligand & & 411 \\
\hline & Low Con. ligand & & 411 \\
\hline
\end{tabular}

* con. Mean is Concentration
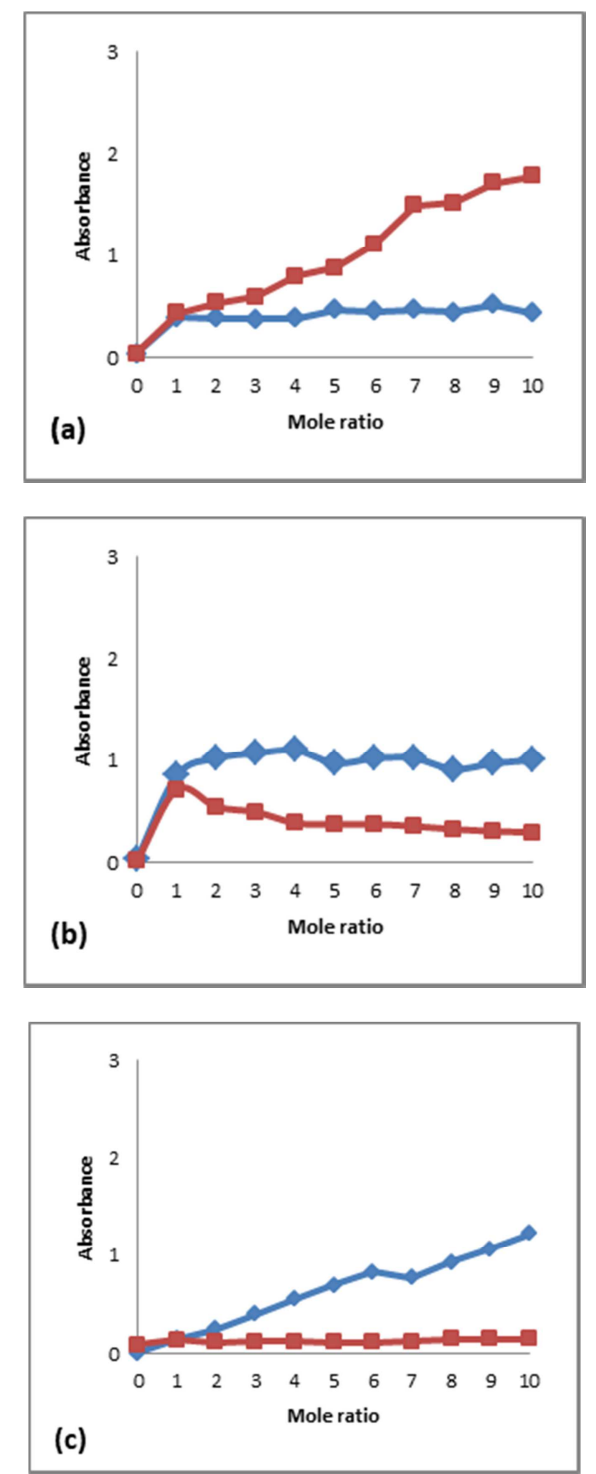

Figure 6. (a) The molar ratio of Fe (III) - Tannic acid, (b). The molar ratio of Fe (III)-extract Oak gall, (c). The molar ratio of Fe (III)-Deferoxamine B, (blue $=$ constant ligand concentration and Red $=$ constant metal concentration).
"Figure 6 (a)" indicates the molar ratio of $\mathrm{Fe}$ (III) Tannic acid. As is evident in the Fig.6, in both cases the molar ratio of low concentrations ligand and high concentration of ligand is $1: 1$, which is one metal was chelated with Tannic acid. "Figure 6 (b)"; indicates the molar ratio of $\mathrm{Fe}$ (III) to extract of Oak gall. This is also evident in "Figure 6 (b)", when the ligand concentration is kept constant and the concentration of the metal increases, the complex has molar ratio 1: 1; Tannic acid gives the same behavior with ligand but when increased the concentration of the ligand (at constant concentration of metal) this behavior is different with Tannic acid. Since oak gall extract containing tannins and they are a polyphenols with different and large group of the phenols so there is a possibility of forming complexes with iron. Therefore, as the iron ions tend to bind with the phenolic groups, it is predicted to formation of the complexes with the stoichiometry of ML2, ML3 and so on with increasing of ligand concentration in solution. "Figure 6 (c)" is related to the molar ratio of Fe (III) - Deferoxamine. In this Fig. is also evident when the metal concentration is low [constant concentration of metal], does not form a complex. In other words, the two ligands (tannic acid, extract) are better formed complexes than Deferoxamine at low concentrations of iron (III). This could be due to the large number of hydroxyl groups in Tannic acid and Oak gall extract. Also, in "Figure 6 (c)", when the ligand concentration is constant and the concentration of the metal increases, we observe the formation of $\mathrm{Fe}(\mathrm{III})$-deferoxamine complex with stoichiometry of 1: 6 .

This suggests that the high ability of complexation of the Deferoxamine at high concentrations of metals. Although the behavior of the graph in a mole ratio of $1: 7$ can be predict by the formation of other ratio complex which it is undeniable due to the broad absorption peak in the "Figure 5".

\section{Conclusion}

Evaluation of antioxidant activity of the Oak gall extract 
with vitamin $\mathrm{C}$ indicates that anti-radical and antioxidant of the Oak gall is comparable. This anti-radical activity is a numerical value at low concentrations (approximately 10 ppm). This amount does not undergo many changes with increasing concentration. Hydroxyl groups in tannins are property of chelating metal ions such as iron and aluminum. The complex formation is depending to the $\mathrm{pH}$. At moderately alkaline $\mathrm{pH}$, the phenolic groups change to phenolate and combined better with the metallic ions. At high alkaline media, the insoluble metal hydroxide such as $\mathrm{Fe}(\mathrm{OH})_{3}$ is formed and precipitate. Therefore, the adjustment of $\mathrm{pH}$ is important. This can be compared with a chelating agent such as Deferoxamine at low concentrations of metal.

\section{References}

[1] Haslam, E. Plant polyphenols. Vegetable Tannins Revisited; Cambridge University Press: Cambridge, U.K., 1989; pp 230.

[2] Hagerman, A. E.; Carlson, D. M. Biological Responses to Tannins and Other Polyphenols. Recent Res. DeV. Agric. Food Chem. 1998, 2, 689-704.

[3] Bi, J. L.; Felton, G. W.; Murphy, J. B.; Howles, P. A.; Dixon, R. A.; Lamb, C. J. Do Plant Phenolics Confer Resistance to Specialist and Generalist Insect Herbivores J. Agric. Food Chem. 1997, 45, 5 [11], 4500-4504.

[4] Hagerman, A. E.; Butler, L. G. Tannins and Lignins. In HerbiVores: Their Interactions with Secondary Plant Metabolites [2nd edition] Volume I, The Chemical Participants; Rosenthal, G. A., Berenbaum, M. R., Eds.; Academic Press: New York, 1991; pp 355-388.

[5] Velioglu, Y. S., Mazza, G., Gao, L., Oomah, B. D., 1998. Antioxidant activity and total phenolics in selected fruits, vegetables and grain products. Journal of Agricultural and Food Chemistry 46, 4113-4117

[6] Sun, B., Fukuhara, M., 1997. Effects of co-administration of butylated hydroxytoluene, butylated hydroxyanisole and flavonoids on the activation of mutagens and drug metabolizing enzymes in mice. Toxicology 122, 61-72.

[7] Wichi, H. P., 1988. Enhanced tumour development by butylated hydroxyanisole [BHA] from the prospective of effect on forestomach and oesophageal squamous epithelium. Food and Chemical Toxicology 26, 717-723.

[8] Sherwin, E. R., 1990. In: Branen, A. L., Davidson, P. M., Salminen, S. [Eds.], Food Additives. Marcel Dekker Inc., New York, p. 139-193.

[9] Shahidi, F., Wanasundara, P. D., 1992. Phenolic antioxidants. Critical Reviews in Food Sciences and Nutrition 32, 67-103.

[10] Chen, C. H., Pearson, A. M., Gray, J. I., 1992. Effects of synthetic antioxidants [BHA, BHT and PG] on the mutagenicity of IQ-like compounds. Food Chemistry 43, 177-183.

[11] Moure, A., Cruz, J. M., Franco, D., Dominguez, J. M., Sineiro, J., Dominguez, H., Nunez, M. J., Parajo, J. C., 2001. Natural antioxidants from residual sources. Food Chemistry 72, 145-171.
[12] Gu" lc in, I., 2006a. Antioxidant activity of caffeic acid [3,4-dihydroxycinnamic acid]. Toxicology 217, 213-220.

[13] Oktay, M., Gu"lc, in, I., Ku freviog lu, O. I., 2003. Determination of in vitro antioxidant activity of fennel [Foeniculum vulgare] seed extracts. Lebensmittel Wissenchaft und-Technology 36, 263-271

[14] Shahidi, F., 2000. Antioxidants in food and food antioxidants. Nahrung 44, 158-163.

[15] Van Ruth, S. M., Shaker, E. S., Morrissey, P. A., 2001. Influence of methanolic extracts of soybean seeds and soybean oil, on lipid oxidation in linseed oil. Food Chemistry 75, 177-184.

[16] Bryngelsson, S., Dimberg, LH., Kamal-Eldin, A., 2002. Effects of commercial processing on levels of antioxidants in oats [Avena sativa L.]. Journal of Agricultural and Food Chemistry 50, 1890-1896.

[17] Cook, N. C., Samman, S., 1996. Flavonoids: chemistry, metabolism, cardioprotective effects and dietary sources. Journal of Nutritional Biochemistry 7, 66-76.

[18] Rice-Evans, C., 1995. Plant polyphenols: free radical scavengers or chain breaking antioxidants? Biochemical Society Symposia 61, 103-116.

[19] Liyana-Pathirana, C. M., Shahidi, F., 2006. Antioxidant properties of commercial soft and hard winter wheats [Triticum aestivum L.] and their milling fractions. Journal of Sciences Food and Agriculture 86, 477-485.

[20] Chung, K. T., Wong, T. Y., Wei, C. I., Huang, Y. W., Lin, Y., 1998a. Tannins and human health: a review. Critical Review in Food Sciences and Nutrition 38, 421-464.

[21] King, A., Young, G., 1999. Characteristics and occurrence of phenolic phytochemicals. Journal of the American Dietetic Association 99, 213-218.

[22] Ferguson, L. R., 2001. Role of plant polyphenols in genomic stability. Mutation Research 75, 89-111.

[23] Wu, L. T., Chu, C. C., Chung, J. G., Chen, C. H., Hsu, L. S., Liu, J. K., Chen, S. C., 2004. Effects of tannic acid and its related compounds on food mutagens or hydrogen peroxide-induced DNA strands breaks in human lymphocytes. Mutation Research 556, 75-86.

[24] Andrade, R. G., Dalvi, L. T., Silva, J. M. C., Lopes, G. K. B., Alonso, A., Hermes-Lima, M., 2005. The antioxidant effect of tannic acid on the in vitro copper-mediated formation of free radicals. Archive of Biochemistry and Biophysics 437, 1-9.

[25] Chen, S. C., Chung, K. T., 2000. Mutagenicity and antimutagenicity of tannic acid and its related compounds. Food and Chemical Toxicology 38, 1-5.

[26] Lopes, G. K. B., Schulman, H. M., Hermes-Lima, M., 1999. Polyphenol tannic acid inhibits hydroxyl radical formation from Fenton reaction by complexing ferrous ions. Biochimica Biophysica Acta 1472, 142-152.

[27] Nepka, C., Sivridis, E., Antonoglou, O., Kortsaris, A., Georgellis, A., Taitzoglou, I., Hytiroglou, P., Papadimitrou, C., Zintzaras, I., Kouretas, D., 1999. Chemopreventive activity of very low dose dietary tannic acid administration in hepatoma bearing $\mathrm{C} 3 \mathrm{H}$ male mice. Cancer Letters 141, 57-62. 
[28] Gali, H. U., Perchellet, E. M., Klish, D. S., Johnson, J. M., Perchellet, J. P., 1992. Hydrolyzable tannins: potent inhibitors of hydroperoxide production and tumor promotion in mouse skin treated with 12-O-tetradecanoylphobol-13-acetate in vivo. International Journal of Cancer 51, 425-436.

[29] Athar, M., Khan, W. A., Mukhtar, H., 1989. Effect of dietary tannic acid on epidermal, lung, and forestomach polycyclic aromatic hydrocarbon metabolism and tumorigenicity in Sencar mice. Cancer Research 49, 5784-5788.

[30] Horikawa, K., Mohri, T., Tanaka, Y., Tokiwa, H., 1994. Moderate inhibition of mutagenicity and carcinogenicity of benzo[a]pyrene, 1,6-dinitropyrene and 3,9-dinitrofluoranthene by Chinese Medicinal Herbs. Mutagenesis 9, 523-526.

[31] Khan, N. S., Hadi, S. M., 1998. Structural features of tannic acid important for DNA degradation in the presence of $\mathrm{Cu}$ [II]. Mutagenesis 13, 271-274.

[32] Khan, N. S., Ahmad, A., Hadi, S. M., 2000. Anti-oxidant, pro-oxidant properties of tannic acid and its binding to DNA. Chemical and Biological Interactions 125, 177-189.

[33] Bezkorovainy A The iron-sulpher proteins, in Biochemistry of Nonheme Iron. Plenum Press, New York, NY, 1980, p 343-347.

[34] Scheibel LW, Sherman I W Metabolism and organellar function during various stages of the life cycle: Proteins, lipids, nucleic acids and vitamins, in Wernsdorfer W, McGregor I [eds]: Malaria: Principles and Practice of Malariology. New York, NY, Churchil Livingstone, 1988, p 219-242.

[35] Wrigglesworth JM, Baum H: The biochemical features of iron, in Jacobs A, Worwood M [eds]: Iron in Biochemistry and Medicine San Diego, CA, Academic, 1980, p 29-86.

[36] Scheibel LW Plasmodial parasite biology: Carbohydrate metabolism and related organellar function during various stages of the life cycle, in Wernsdorfer W, McGregor I [eds]: Malaria: Principles and Practice of Malariology. New York, NY, Churchil Livingstone, 1988, p 171.

[37] Wernsdorfer WH, Trig PI: Recent progress of malaria research: Chemotherapy, in Wernsdorfer W, McGregor I [eds]: Malaria: Principles and Practice of Malariology. New York, NY, Churchill Livingstone, 1988, p 1569-1573.

[38] Disler, P. B., Lynch, S. R., Torrance, J. D., Sayers, M. H., Bothwell, T. H. and Charlton, R. W. [1975b] The mechanism of the inhibition of iron absorption by tea. South African Journal of Medical Sciences 40, 109-1 16.

[39] Brune, M., Hallberg, L. and Skanberg, A. [1991] Determination of iron binding by phenolic groups in foods. Journal of Food Science 56, 128-167.

[40] Mejbaum-Katzenellenbogen, W. and Kudrewicz-Hubicka, Z. [1966] Application of urea, ferric ammonium sulfate and casein for determination of tanning substances in plants. Acta Biochimica Polonica 13, 57-67.

[41] Modell B, Berdoukas V Deferoxamine, in The Clinical Approach to Thalassemia. Philadelphia, PA, Grune and Stratton, 1984, p 216.

[42] Brittenham GM: Iron chelating agents, in Brian MC, McCulloch PB [eds]: Current Therapy in Hematology Oncology 3. St Louis, MO, Mosby, 1987, p 149. 